\title{
Comparative Study for Grinding of Two Cement Clinkers
}

\author{
Soumaya Ibrahimi, ${ }^{1), *}$ Néjib Ben Jamaa, ${ }^{1)}$ Khaoula Mliki, ${ }^{1)}$ and Mohamed Bagane ${ }^{2)}$
}

(Received May 30 2011, Revised August 26, 2011, Accepted August 26, 2011)

\begin{abstract}
The purpose of this work is the comparative study for grinding of two cement clinkers. X-ray fluorescence, physical and granulometric tests and optical microscopy were used to characterize the clinkers. Also grinding tests were carried out for ten samples to determine the parameters influencing grindability of its clinkers. The results of calculation of the energies of grinding according to the law developed by Von Rittinger and the study of the microstructure of the two clinkers shows good agreements. Indeed, frequent clusters of belite which indicate a lack of uniformity and fineness have an effect on lowering the grindability. The obtained analyses and the results enabled us to interpret the granulometry and the microstructure of clinker to control quality and resistance.
\end{abstract}

Keywords: cement, clinker, grindability, X-ray fluorescence, optical microscopy.

\section{Introduction}

The aim of this work is the study for the aptitude of grinding of two cement clinkers. These clinkers were processed in two cement plants. To keep the rate of the cement production in the plant $\mathrm{N}^{\circ} 1$ as constant as possible, while the kiln is in a technical arrest, clinker from à second plan was carried out and was grinded. The grinding of clinker represents a step of manufacture of cement which consumes about one-third of the power required to produce 1 ton of cement. This refers to an average specific power conception of $57 \mathrm{kWh} / \mathrm{t}^{1}$. The following factors all affect the grinding properties of the material to vary degrees: ${ }^{2}$

- The hardness of material expressed on Moh's scale from 1 to 10;

- Abrasiveness: highly abrasive material requires lower mill rotation speeds,

- Toughness or Brittleness managing the resistance to crack propagation;

- Cohesivity (related to a lower particle size and moisture content);

- Carrier medium;

- Milling circuit, closed with multiple passes or open and single pass;

- Melting point of material and

- Fibrous material.

We can note that the hardness of mineral phases constituting the clinker decrease in this order: aluminoferrite $\left(\mathrm{C}_{4} \mathrm{AF}\right)$, the belite type II $\left(\mathrm{C}_{2} \mathrm{~S}\right)$, the aluminate $\left(\mathrm{C}_{3} \mathrm{~A}\right)$, the alite $\left(\mathrm{C}_{3} \mathrm{~S}\right)$ and the belite type I. Consequently, the belite type I presents the lowest Vickers

\footnotetext{
${ }^{1)}$ Environment Catalyses and Analyzes of Processes Unit Research, National School of Engineering of Gabes, University of Gabes, 6029, Tunisia. *Corresponding Author; E-mail: ibrahimi. soumaya@gmail.com

${ }^{2}$ Applied Thermodynamics Unit Research, Gabes 6029, Tunisia. Copyright (c) 2011, Korea Concrete Institute. All rights reserved, including the making of copies without the written permission of the copyright proprietors.
}

hardness. It is interressant to note also that this hardness is influenced by the presence or not of the inclusions in the phase and of its vicinity. ${ }^{3}$ The distribution of the phases of clinker plays a very significant role in grinding. More the phases distributed uniformly over the grinding of clinker will be easy. The clusters of $\mathrm{C}_{2} \mathrm{~S}$ that result from a heterogeneous raw material will also play an important role. In this work, we treated a series of samples in order to extract the maximum of information on the two studied clinkers characteristics. Thus, a detailed study is made on the chemical and mineralogical properties of clinker using the techniques of X-ray fluorescence and optical microscopy. Grinding tests was also carried out to determine the influence of granulometry on the grindability of the clinker.

\section{Preparation of samples}

In this study we used a standard ball mill uncoated type TTS. It is cylindrical in shape and his weight, including steel balls, is 380 $\mathrm{kg}$. Samples that were the subject of this study were classified into several size fractions: $>20 \mathrm{~mm}, 10 \sim 20 \mathrm{~mm}, 5 \sim 10 \mathrm{~mm},<5 \mathrm{~mm}$ and the crude. For each grinding test, the ball mill is fed with a load of: $1,425 \mathrm{~g}$ of clinker combined with $75 \mathrm{~g}$ of gypsum, and then rotated for 10 minutes of grinding and 3 minutes of discharge at a rate of $50 \mathrm{rpm}$. We used the law developed by von Rittinger to compare the energies of grinding. The comparison of the behavior of crude on the grinding for different size fractions allowed us to make the choice of representative size fractions of each clinker. ${ }^{2}$ In most cases, the microscopic observation of cement clinker is done in reflected light. ${ }^{4}$ So the preparation of polished sections is necessary. We take four to five nodules of clinker which are placed in a cylindrical mold made of polyethylene, $40 \mathrm{~mm}$ in diameter and $30 \mathrm{~mm}$ in height. Theses clinkers were completely immersed in a cold mounting resin. After 20 minutes of impregnation, we obtain a pellet clinker. The sample is cut with the saw to bring up the nodules and get a flat section of clinker. This section was ready for polishing on disc by using abrasive paper with adhesive reverse of number $320,400,600,800,1,000$ and $1,200 \mu \mathrm{m}$ 
respectively until obtaining an increasingly polished section. The final phase of polishing is done on cloth by using an alumina suspension, diluted with alcohol and acting as a lubricant. Then the section is washed with alcohol in an ultrasonic cleaner. ${ }^{5}$

\section{Tests of grinding}

The effect of granulometry on the aptitude of the crushing of the clinker which represents the problem of the test of crushing carried out for the clinker $\mathrm{N}^{\circ} 2$, constitutes the basic idea for our discussion. First of all, we try to determine the class of particle-size representative for each type of cement while basing ourselves on the results obtained in this part of work. Whereas the clinker $\mathrm{N}^{\circ} 1$, the sections $>20$ and $10 \sim 20 \mathrm{~mm}$ was the closest to the crude and are almost confused and which reach $67 \%$ of the totality of the samples and the remainder was for the sections $<5$ and $5 \sim 10 \mathrm{~mm}$ which is the easiest to crush (Fig. 1). Whereas the clinker $\mathrm{N}^{\circ} 1$, the sections $>20$ and 10 20 mm was the closest to the crude and was almost confused and which reach $67 \%$ of the totality of the samples and the remainder was for the sections $<5$ and $5 \sim 10 \mathrm{~mm}$ which is easiest to crush (Fig. 1). Thus, the granulometry of the clinker $\mathrm{N}^{\circ} 1$ can be considered as average.

However, for the clinker $\mathrm{N}^{\circ} 2$ the section $10 \sim 20 \mathrm{~mm}$ is the closest to the crude and which reach $79 \%$ of the refusal whereas the section $>20 \mathrm{~mm}$ exceeded the crude to reach $84 \%$ (Fig. 2).

Thus, the clinker $\mathrm{N}^{\circ} 2$ gives a clinker difficult to crush with an initial average diameter equal to $19.27 \mathrm{~mm}$ and a final average diameter estimated at $4.990 \mathrm{~mm}$. However the clinker $\mathrm{N}^{\circ} 1$ is

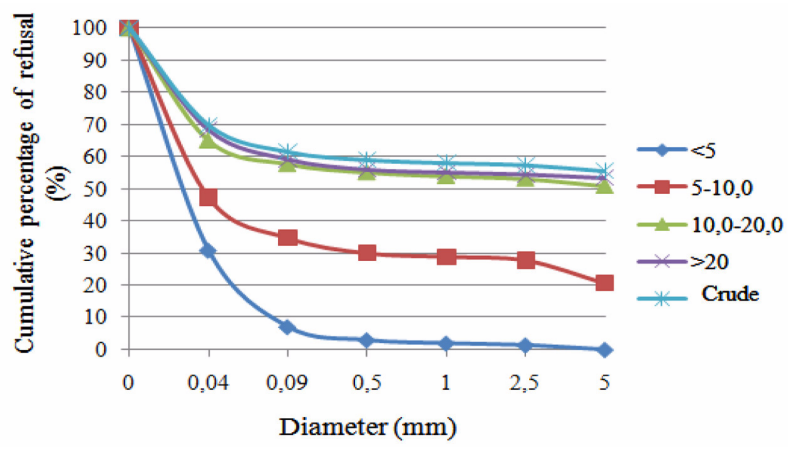

Fig. 1 Grading curve of the refusal of Clinker $N^{0} 1$. The samples were classified into several size fractions: $>20 \mathrm{~mm}, 10 \sim$ $20 \mathrm{~mm}, 5 \sim 10 \mathrm{~mm},<5 \mathrm{~mm}$ and the crude.

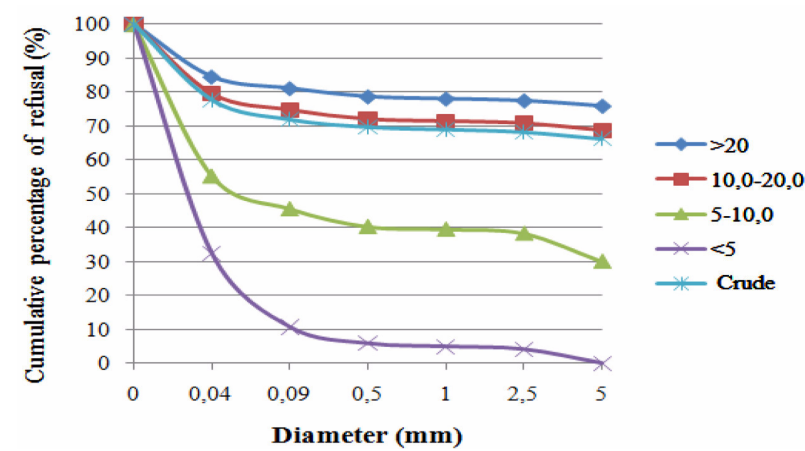

Fig. 2 Grading curve of the refusal of Clinker $\mathrm{N}^{\circ} 2$. The samples were classified into several size fractions: $>20 \mathrm{~mm}, 10 \sim$ $20 \mathrm{~mm}, 5 \sim 10 \mathrm{~mm},<5 \mathrm{~mm}$ and the crude. easier to crush with an initial diameter $17.67 \mathrm{~mm}$ and a final average diameter $4.97 \mathrm{~mm}$. It appears clear that for the same conditions of crushing (time of crushing, charges...) the clinker $\mathrm{N}^{\circ} 2$ spends more energy to transfer the grains from the initial size to another smaller.

We can draw that granulometry is one of the factors which affects grindability of the clinker $\mathrm{N}^{\circ} 2$. Then, we made a study of the samples by class of particle-size. The refusal of the clinker $\mathrm{N}^{\circ} 2$ is higher than that of the clinker $\mathrm{N}^{\circ} 1$ for the openings of sieve $\geq$ $2.5 \mathrm{~mm}$. That stresses the idea of the hardness of the clinker $\mathrm{N}^{\circ} 2$ compared to that of the clinker $\mathrm{N}^{\circ} 1$. This hardness is due to a high cooking of the entering load (high weight of liter) as it can be the result of a variation in the chemical composition. In addition it was noted that the masses of the refusal of the clinker $\mathrm{N}^{\circ} 2$ are remarkably lower compared to that of the clinker $\mathrm{N}^{\circ} 1$ between the openings of sieve 0.09 and $0.04 \mathrm{~mm}$, making it possible to give him a better smoothness and consequently an increase in the compressive strength in long-term (Fig. 3). Being given that the specific surface of Blaine is one of the physical parameters which can influence the mechanical resistance of cement, the test of Blaine shows that the values of the SSB of the clinker $\mathrm{N}^{\circ} 2$ are higher than those of the clinker $\mathrm{N}^{\circ} 1$. So this higher smoothness generates a more significant resistance. Moreover, the results of the mechanical test show that cements of the two factories have very close flexural strengths and that cement $\mathrm{N}^{\circ} 2$ develops a better compressive strength and this for 2, 7 and 28 days and consequently cement $\mathrm{N}^{\circ} 2$ has a larger resistance in the long run (Fig. 3).

According to Table 1, which provides results of the analyses by Fluo $\mathrm{X}$ for all the samples which were the subject of grinding, we can draw the following interpretations: Initially, the various modulates are in the margin except the hydraulic module which appears exceeded and so it can influence the stability of volume and can lead to a phenomenon of swelling. In the second place, there are an abundance of $\mathrm{C}_{3} \mathrm{~A}$ and $\mathrm{C}_{4} \mathrm{AF}$ for the clinker $\mathrm{N}^{\circ} 2$ what accelerates the kinetics of the reaction of clinkerisation in the furnace and can influence grindability. Lastly, the increase in the alumina module for clinker $\mathrm{N}^{\circ} 1$ compared to the clinker $\mathrm{N}^{\circ} 2$, confirmed by a small degree of combination of $\mathrm{CaO}$, influences the granulation and indicates an increase to the level of the temperature of clinkerisation. Thus at this stage, we think that granulometry cannot be the only factor responsible for the problem of crushing. This will take along to try to remove ambiguities by using other techniques like Fluo $\mathrm{X}$ and optical microscopy.

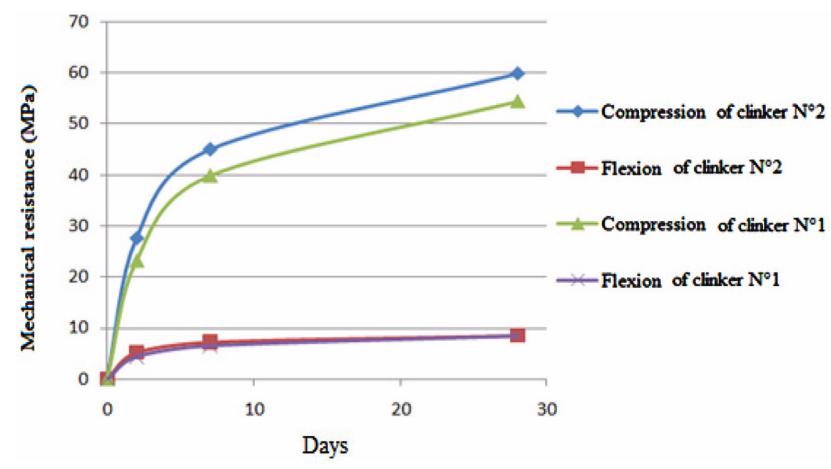

Fig. 3 Mechanical resistance of cement. 
Table 1. Chemical composition of the different clinkers (wt \%) determined by XRF. The clinkers come from two different cement plants $\mathrm{N}^{\circ} 1$ and $\mathrm{N}^{\circ} 2$.

\begin{tabular}{|c|c|c|c|c|c|c|c|c|}
\hline \multirow[b]{2}{*}{ SampleN $^{\circ}$} & \multicolumn{4}{|c|}{ Clinker $\mathrm{N}^{\circ} 1$} & \multicolumn{4}{|c|}{ Clinker $\mathrm{N}^{\circ} 2$} \\
\hline & 1 & 2 & 3 & 4 & 1 & 2 & 3 & 4 \\
\hline $\mathrm{CaO}$ & 65.96 & 67.19 & 67.47 & 66.57 & 65.76 & 65.87 & 67.53 & 67.49 \\
\hline $\mathrm{SiO}_{2}$ & 22.24 & 22.06 & 22.25 & 21.72 & 21.33 & 21.47 & 21.99 & 21.8 \\
\hline $\mathrm{Al}_{2} \mathrm{O}_{3}$ & 4.79 & 4.36 & 4.57 & 4.99 & 6.11 & 5.91 & 4.62 & 4.68 \\
\hline $\mathrm{Fe}_{2} \mathrm{O}_{3}$ & 3.24 & 3.02 & 3.16 & 3.09 & 3.38 & 3.25 & 3.16 & 3.25 \\
\hline $\mathrm{SO}_{3}$ & 1.24 & 0.76 & 0.37 & 1.13 & 0.70 & 0.71 & 0.30 & 0.31 \\
\hline $\mathrm{K}_{2} \mathrm{O}$ & 0.55 & 0.42 & 0.31 & 0.57 & 0.61 & 0.60 & 0.30 & 0.30 \\
\hline $\mathrm{Cl}$ & 0.0143 & 0.0140 & 0.0151 & 0.0131 & 0.0149 & 0.0169 & 0.0120 & 0.0117 \\
\hline $\mathrm{MgO}$ & 1.39 & 1.32 & 1.34 & 1.35 & 1.10 & 1.11 & 1.34 & 1.34 \\
\hline $\mathrm{TiO}_{2}$ & 0.25 & 0.23 & 0.24 & 0.25 & 0.26 & 0.25 & 0.24 & 0.24 \\
\hline $\mathrm{Na}_{2} \mathrm{O}$ & 0.11 & 0.10 & 0.09 & 0.11 & 0.10 & 0.10 & 0.10 & 0.10 \\
\hline Total & 99.78 & 99.47 & 99.82 & 99.79 & 99.36 & 99.29 & 99.59 & 99.52 \\
\hline Free lime & 2.17 & 0.70 & 0.88 & 1.43 & 1.07 & 1.07 & 0.46 & 0.48 \\
\hline HRS & 24.29 & 22.08 & 23.15 & 25.40 & 31.23 & 30.22 & 23.41 & 23.70 \\
\hline $\mathrm{C}_{\mathrm{i}} \mathrm{S}$ & 76.50 & 80.07 & 80.18 & 77.14 & 74.67 & 75.28 & 80.36 & 79.97 \\
\hline $\mathrm{C} / \mathrm{S}$ & 2.97 & 3.05 & 3.03 & 3.06 & 3.08 & 3.07 & 3.07 & 3.10 \\
\hline $\mathrm{C}_{3} \mathrm{~S}$ DRX & 46.70 & 70.70 & 68.20 & 58.80 & 52.60 & 56.00 & 72.40 & 73.30 \\
\hline $\mathrm{C}_{2} \mathrm{~S}$ DRX & 26.60 & 15.90 & 16.00 & 21.10 & 21.80 & 21.40 & 14.30 & 14.00 \\
\hline $\mathrm{C}_{3} \mathrm{~S}$ & 51.50 & 68.13 & 66.34 & 60.18 & 54.68 & 55.55 & 70.11 & 70.75 \\
\hline $\mathrm{C}_{2} \mathrm{~S}$ & 25.00 & 11.94 & 13.83 & 16.96 & 19.99 & 19.74 & 10.24 & 9.22 \\
\hline $\mathrm{C}_{3} \mathrm{~A}$ & 7.22 & 6.45 & 6.77 & 8.00 & 10.48 & 10.17 & 6.90 & 6.91 \\
\hline $\mathrm{C}_{4} \mathrm{AF}$ & 9.85 & 9.18 & 9.61 & 9.39 & 10.28 & 9.88 & 9.61 & 9.88 \\
\hline $\mathrm{AM}$ & 1.48 & 1.44 & 1.45 & 1.61 & 1.81 & 1.82 & 1.46 & 1.44 \\
\hline $\mathrm{SM}$ & 2.77 & 2.99 & 2.88 & 2.69 & 2.25 & 2.34 & 2.83 & 2.75 \\
\hline LSF & 94.19 & 97.55 & 96.74 & 96.88 & 95.12 & 95.18 & 97.76 & 98.27 \\
\hline HM & 3.19 & 3.24 & 3.24 & 3.36 & 3.54 & 3.50 & 3.29 & 3.31 \\
\hline
\end{tabular}

HRS: Relation between tricalcium aluminate and aluminate tetracalcic, XRD: X - Ray Diffraction, AM: Aluminoferrique Modulate, SM: Silicic Module, LSF: Lime Saturation Factor and HM: Hydraulic Modulate.

\section{Characterization under the optical microscope}

By taking account of the resemblance of the various phases of the clinker, a surface chemical attack must be made on all the samples in order to make appear the various phases of the clinker. The crystals of alite $\left(\mathrm{C}_{3} \mathrm{~S}\right)$ are prismatic, those of belite $\left(\mathrm{C}_{2} \mathrm{~S}\right)$ are rounded and the interstitial mass $\left(\mathrm{C}_{3} \mathrm{~A}+\mathrm{C}_{4} \mathrm{AF}\right)$ is clear. In our study, we choose the eight samples of crushing and also ten samples among the twenties, already taken to treat, to be attacked with hydrofluoric acid (Fig. $4 \mathrm{a}$ and $4 \mathrm{~b}$ ) and nitric acid $\mathrm{HNO}_{3}$ with $0.25 \%$ in alcohol (Fig. 5a and 5b).

\subsection{Attack by the vaporized hydrofluoric acid}

After its polishing, the section is exposed to the vapor of hydrofluoric acid during 10 to $20 \mathrm{~s}$ then ventilated by a water vapor using hair dryer to avoid the deterioration of the objectives of the microscope. ${ }^{4}$ The crystals of alite $\left(\mathrm{C}_{3} \mathrm{~S}\right)$ are prismatic, sometimes tabular, cover the majority of surface observed and their size varying between 13 and $70 \mu \mathrm{m}$. They contain sometimes inclusions of belite $\left(\mathrm{C}_{2} \mathrm{~S}\right)$. The crystals rounded of belite are striated and frequently grouped in cluster and their size varies from 10 to $40 \mu \mathrm{m}$. The most widespread phase in the industrial clinkers is the phase $\beta$. They show sometimes a digitation due to a reaction of fusion and testifying to a slow cooling of the clinker. ${ }^{6}$ Aluminate $\left(\mathrm{C}_{3} \mathrm{~A}\right)$ appears gray in a clearer matrix consisted of alumino-ferrite $\left(\mathrm{C}_{4} \mathrm{AF}\right)$.

\subsection{Interpretations of microstructure}

The observation of the fine texture of the clinker obtained via optical microscopy makes it possible to follow the parameters managing the manufacturing process in the furnace what makes it possible to improve quality of cement. The determination of the potential phases of the clinker on a microscopic image becomes easier with the chemical attacks carried out on the samples to analyze. The alite $\left(\mathrm{C}_{3} \mathrm{~S}\right)$ has a prismatic texture and allows controlling the parameters of heating in the furnace. The bélite appears round and dependent with alite by the interstitial mass; it informs on the stage of cooling. By taking account of the difference of the areas of the two types of clinker $\mathrm{N}^{\circ} 1$ and $\mathrm{N}^{\circ} 2$ 


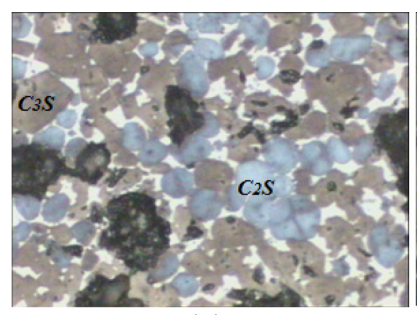

(a)

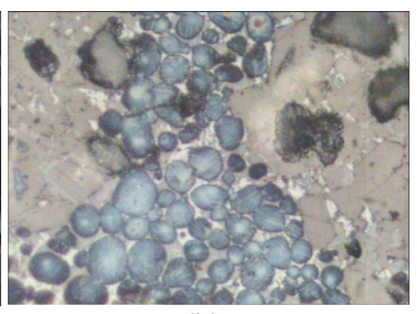

(b)
Fig. 4 (a) Micrography of the clinker $\mathrm{N}^{\circ} 2$, Polished section attacked by the vaporized hydrofluoric acid (40\%). The crystals of belite are rounded and blue. The crystals of alite are prismatic and brown. The interstitial mass is well crystallized and white. The pores are black, (x100). (b) Micrography of the clinker $\mathrm{N}^{0} 2$. Polished section attacked by the vaporized hydrofluoric acid $(40 \%)$. Heterogeneous distribution of the phases. Cluster of belite, (x200).

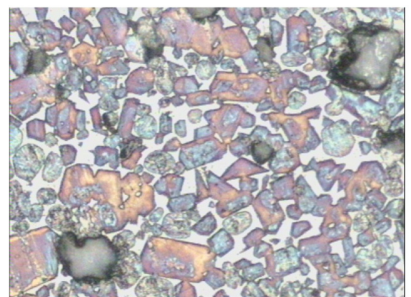

(a)

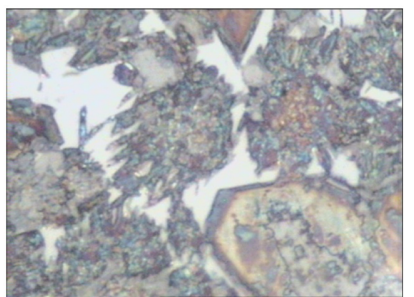

(b)
Fig. 5 (a) Micrography of the clinker $\mathrm{N}^{\circ} 1$. Homogeneous distribution of the phases, $(x 100)$. Polished section attacked with a nitric acid solution in alcohol. The prismatic alite is light blue, the round belite is blue dark and the interstitial mass is white, (x100). (b) Micrography of the clinker $\mathrm{N}^{0} 1$. Polished section attacked with a nitric acid solution in alcohol. Digitations of C2S, (x400).

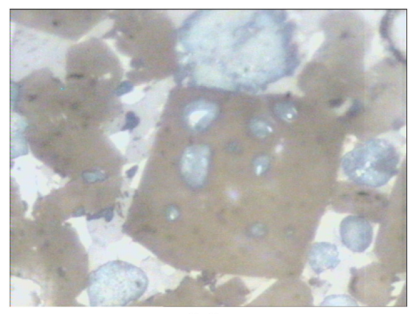

(a)

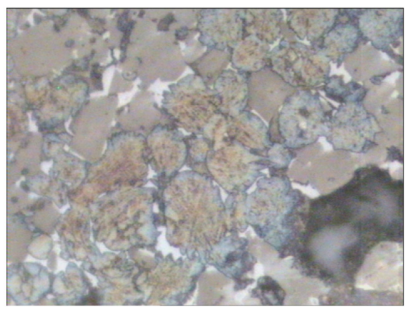

(b)
Fig. 6 (a) Micrography of the clinker $\mathrm{N}^{\circ} 2$. Polished section attacked by the vaporized hydrofluoric acid (40\%). Abundance of inclusions of belite in the crystals of alite, (x400). (b) Micrography of the clinker $\mathrm{N}^{\circ} 2$. Polished section attacked by the vaporized hydrofluoric acid $(40 \%)$, The rounded crystals of belite appear striated (blue). The crystals of alite are brown. The interstitial mass is well differentiated, (x200).

and of the problem encountered with the grinding of the clinker $\mathrm{N}^{\circ}$ 2, we waited until the chemical composition of the components as well as the fine texture of the two types of clinker are different. That requires an in-depth study for each type of clinker.

The observation of the microscopic images of the clinker $\mathrm{N}^{\circ} 1$ enables us to gather following information: The distribution of the various phases of the clinker is almost homogeneous (Fig. 5a), the alite is prismatic, the belite is round and the interstitial mass is well differentiated. So the conditions of manufacture in the furnace are acceptable, the chemical composition of the vintage is correct, well mixed vintage, the particles are not coarse, as well as the temperatures of heating and of cooling are satisfactory. But that does not exclude the existence of the clusters of belite near large crystals of alite resulting from a slow heating. These phenomena are frequent and due to the weak variations of the parameters of production which are difficult to maintain always fixed during the walk of the furnace. We observe also transformations of phase $\mathrm{C}_{3} \mathrm{~S}$ into $\mathrm{C}_{2} \mathrm{~S}$. Digitations are formed on the belite (Fig. 5b) and also inclusions of belite in alite are observed. This transformation could reduce the resistance in short-term of cement and influence the time of cooling of the clinker. These phenomena remain weak compared to those observed in the clinker $\mathrm{N}^{\circ} 2$. If we refer to the analysis by Fluo $\mathrm{X}$, we note that the concentration of $\mathrm{SO}_{3}$ was high, for the launching period of the furnace before the establishment of the regular mode, which can be at the origin of broad pores, belite dispersed and large crystals of alite are observed in the majority of the samples of the clinker $\mathrm{N}^{\circ} 1 .^{8-9}$ The identification of the phases on a microscopic image enables us to make a synthesis of the fine texture of the clinker $\mathrm{N}^{\circ} 2$, so that we can detect the anomalies met in the manufacturing process of cement (for example: cooking, crushing...). In the majority of the samples, the distribution of the various phases is heterogeneous; the crystals of alite appear tubular and damaged. They show in certain cases a zonation. The crystals of alite present an unstable mode of growth whose morphology is irregular and containing a great quantity of round inclusions of belite (Fig. 6a). Transformations of alite in belite are rather remarkable witnessing a transformation during a slow cooling. The crystals of belite have a variable forms sometimes round and of another time notched. They are frequently striated and show a digitation (Fig. 6b) due to maintenance to a long time at high temperature, also justified by a high weight of the liter for all the samples, and testifying to a slow cooling of the clinker. ${ }^{6}$ Crystals of $\mathrm{C}_{2} \mathrm{~S}$ are located on the edges of those of $\mathrm{C}_{3} \mathrm{~S}$ and appear increasing with their detriment. This phenomenon is due primarily at a relatively slow speed of cooling. However the notable reduction in $\mathrm{C}_{3} \mathrm{~S}$ can generate a low compressive strength of cement. The clusters of belite and of alite rather remarkable result, generally, either of a bad homogenization of the raw material or of a bad crushing of the raw mixture, especially when dimensions of the particles are excessively large in the raw mixture (diameter of grain larger than $0.1 \mathrm{~mm})^{4}$ (Fig. 4b). Indeed, the large crystals of silica $\left(\mathrm{SiO}_{2}\right)$ or of lime $(\mathrm{CaO})$ are at the base of this phenomenon. In the samples of the clinker $\mathrm{N}^{\circ} 2$ the phases are small, badly formed, porosity is average, the distribution of the phases is irregular, alite is surrounded by great quantities of liquid phase where the $\mathrm{C}_{3} \mathrm{~A}$ appears gray in a clearer matrix composed of $\mathrm{C}_{4} \mathrm{AF}$ (Fig. 6a) and the belite exists in clusters what makes difficult the crushing of the clinker.

\section{Conclusions}

This study was carried out in the framework of a research project having for goal the comparison between two clinkers which classified into several grades. This work rests on a bibliographical study which is used for the analysis of the results, followed by an experimental study primarily made up of two 
parts. Initially, a test of crushing is carried out by stressing the effect of the difference of granulometry on the difficulty of grndinging. In the second place we had recourse to optical microscopy in the identification of the various potential phases of the clinker (alite, belite, aluminate and ferrite) and to make a dimensional analysis of these phases. Thus, we established a relation between these characteristics, on one hand, the quality and the resistance of the two types of cement as well as the anomalies met in the crushing and in the manufacturing process on the other hand. At this level, we can conclude that the variations between the two clinkers especially on the level of crushing are due to several characteristics such as: granulometry, the chemical composition, the minor elements (alkali, free lime), burning conditions thus it is a whole matrix which is responsible for the differences met at the time of the study of these two types of clinker. So it is necessary to have for the spirit that a well done nodule of the clinker must have a uniform distribution of the crystals of alite generally small, a microporosity well developed in the matrix and especially to have a mix vintage well homogenized and relatively stable conditions of manufacture. Finally, if we analyze the recent past, we note that the techniques used to follow morphology, to measure the sizes as well as to quantify the mineralogical phases of the clinker, underwent successive improvements to give the most relevant information. Among the most advanced techniques, we can improve this work by the use of diffraction of x-rays. This technique allows the identification of the crystalline phases and their quantification while being based on the Rietveld method.

\section{Acknowledgements}

The authors wish to thank the Cement Company of Gabes for the material support. The work was supported financially by the Tunisian Libyan Project on cement quality.

\section{References}

1. Seebach MV., Schneider L., Update on finish grinding with improved energy efficiency. World Cem., Vol. 17, No. 8, 1986, pp. $336 \sim 46$.

2. Rhodes M., Introduction to Particels Technology, John Wiley \& Sons, Brisbane, 1998.

3. De Souza V.C.G, Koppe J. C., Costa J.F.C.L., Vargas A.L.M., Blando E., Hübler R., The influence of mineralogical, chemical and physical properties on grindability of commercial clinkers with high $\mathrm{MgO}$ level. Cement and Concrete Research, 38, 2008, pp. 1119 1125.

4. Donald H. Campbell, Microscopical Examination and Interpretation of Portland Cement and Clinker, Portland Cement Association, Second Edition, SP030, 30 128, 1999.

5. Ben Jamaa N. and Maki I, Characterization of Tunisian Portland cement clinkers by optical microscopy, SEM and microprobe analysis, Ann. Chim. Sci. Mat., Vol. 31, No. 4, 2006, pp. 421 430.

6. Maki I. Processing conditions of Portland cement clinker as viewed from the fine textures of the constituent minerals. $\mathrm{Am}$. Ceram. Soc., 40, Ceramic transactions, 1994, pp. 3 17.

7. Maki I., Some characteristic microscopic textures of the Portland cement constituent minerals and the processing conditions in the kiln, Proc. 23rd Int. Conf. Cement Microscopy 2001.

8. Hofmänner F., Microstructure of Portland Cement Clinker, Holderbank Management and Consulting, Ltd., Holderbank, Switzerland, 1973.

9. Tsuboi T., and Ogawa T., Microscopic Studies of Clinker for Evaluating the Sintering Process, Zement-Kalk-Gips, Vol. 25, No. 6, 1972, pp. 292 294. 